\title{
Chemistry for cultural heritage: connecting past and future
}

Elena Badea ${ }^{1,2^{*}}$

Chemistry plays a multi-faceted role in understanding, protecting and transmitting the legacy of physical artefacts we inherited from past generations. Chemists are called to contribute to solving some of the challenges that face heritage today, from the composition and structure of heritage materials-information from whom provenance, period of creation, manufacturing technology and art techniques could be inferred-to preserving, protecting and securing artefacts against natural catastrophes and man-made disasters.

The tremendous developments in chemical imaging in the last decades and advances in the analytical capabilities of spectroscopic \& chromatographic methods, the potential of nanotechnologies and nanomaterials to enormously improve the traditional conservation and restoration methods and to contribute to the development of new diagnostic methods as well as the increased availability and popularity of portable non-invasive instrumentation have catalyzed innovation in the research of cultural heritage and provided new solutions and perspectives in its documentation, interpretation and cultural uses. Besides, the new cross-disciplinary vision encompassing chemistry, conservation science, archaeological science, bioarcheology, environmental science, physical and engineering sciences, and ICT enables the establishment of new relationships between cultural heritage and its meaning, history, value, significance, composition, conservation and enjoyment. This helps fostering the role of cultural heritage as a key factor for better understanding our history, traditions and culture, an instrument of

\footnotetext{
*Correspondence: elena.badea@unito.it

${ }^{1}$ Advanced Research for Cultural Heritage Laboratory (ARCH Lab),

National Research and Development Institute for Textile and Leather, Division Leather and Footwear (INCDTP-ICPI), Str. Ion Minulescu 93, 031215 Bucharest, Romania

Full list of author information is available at the end of the article
}

cohesion of our diversified community, and not least an element of individual and social wellbeing.

It is within this context that the EuChemS Working Party on Chemistry for Cultural Heritage (ChemCH) initiated in 2010 the International Congress "Chemistry for Cultural Heritage" with the aim of developing relationships across all disciplines relating to chemical science and cultural heritage and across all sectors-academic, business, educational, communications and policy-and helping to put the right people "in the same room".

Since then, the ChemCH congress is organized every other year. The 5 th edition of the congress, ChemCH 2018, was held from 3 to 7 July, 2018, at the Central University Library of Bucharest, Romania. The congress was organized by the Romanian Association "Science and Cultural Heritage in Connection" in collaboration with National Research \& Development Institute for Textiles and Leather through its Advanced Research for Cultural Heritage (ARCH Lab) Group and National Museum of Romanian Literature, under the auspices of the Romanian Chemical Society. The event chaired by Dr. Elena Badea and her team received the patronage of the Romanian Ministry of Research and Innovation.

After successful editions in Ravenna, Italy (2010), Istanbul, Turkey (2012), Vienna, Austria (2014) and Bruxelles, Belgium (2016), this time Bucharest gathered 165 participants, renowned scientists, leading experts in a wide range of chemistry fields as well as young researchers from 19 European countries, China, USA, Singapore, Mexico, Iran and Egypt, extending both the thematic and geographical span. It is worth noting that $62 \%$ of the participants came from the academic (35\%) and research (27\%) institutions, while $34 \%$ of the participants were professionals from museums, libraries, archives (28\%) and private conservation laboratories $(6 \%)$. The participants from various national public institutions accounted 
for $4 \%$. It is also worth of note that $17 \%$ of participants were Ph.D. students and postdoc researchers.

Topics focusing on chemical imaging, nanotechnologies for diagnostic, nanomaterials for conservation and restoration, development of mobile non-invasive/microinvasive analytical methods, development of improved spectroscopic \& chromatographic methods, chemical interaction of environment and artworks \& alteration phenomena, modern art materials, chemometrics on artwork studies, self-boundaries for safe analysis were discussed in 49 oral and 70 poster presentations over 3 days.

The congress provided a platform for fruitfully exchanging experience and ideas, questioning the current and new methodologies, discussing innovative approaches in the proposed topics, finding new solutions to old problems, as well as establishing new collaborations. Moreover, the local organisers took up the momentum created by the European Year of Cultural Heritage to encourage people to explore the Romanian traditions, memories and monuments of Romanian past by offering a rich cultural program. From these memories our common European sense of history is born, from these memories we can learn a lot and draw inspiration to build up a united Europe.

The 25 papers of this collection presented by 134 authors from 18 countries open a window to the multifaceted role of chemistry in the cross-disciplinary field of cultural heritage. They are, for the most part, highly collaborative researches, most papers presenting the results of international collaborations (i.e. 13 papers are signed by authors from 2 countries and 2 papers are signed by authors from 3 and 5 different countries) and thus demonstrating the importance of cross-disciplinary, crossinstitutional and international collaborations. Only 4 papers are signed by authors from a single institution.

The articles can be grouped according to the topic addressed. Some authors aimed to characterize and/or identify historical material and modern materials to (i) obtain information on artefacts provenance and creation period, ancient recipes or industrial formulations of composite materials, manufacturing techniques, (ii) study the painters' techniques, (iii) decide the most appropriate conditions for storing and displaying. Marcaida et al. [1] implemented an in situ non-invasive multi-technique approach based on DRIFT spectroscopies, HH-EDXRF spectrometry and LIBS spectroscopy for characterising Pompeian tesserae. La Nasa et al. [2] reported a new comprehensive approach for the characterisation of multi-material (polymers, paint binder, pigments) modern artworks using analytical pyrolysis (Py-GC/MS and EGA/MS), non-destructive ATR-FTIR and highperformance liquid chromatography (HPLC-DAD and HPLC-ESI-MS). A multi-analytical approach was used by Manea et al. [3] for investigating 64 prehistorical clay weights from three archaeological sites located in Romania: X-ray CT scans coupled with statistical analysis together with technological analysis and experimental archaeology revealed the entire chaîne operatoire of clay weights from various sites. Artesani et al. [4] proposed a combined-microscopy approach based on time-resolved photoluminescence (TRPL) micro-imaging and microRaman spectroscopy for studying a corpus of stratigraphic micro-samples from Russian Avantgarde modern paintings which allowed them to identify several inorganic pigments. Identification of azurite pigment and the binding media by reflection-FTIR method was the aim of the study carried out by Vetter et al. [5] on medieval illuminated manuscripts belonging to Austrian National Library and Wien Museum. Albrecht et al. [6] used the quantitative elemental analysis of the ground layer composition of 39 paintings and PCA analysis for an in-depth technical and art historical research of Jan Steen's oeuvre. Caruso et al. [7] brought new insights into the paintings of Harriet Backer by characterising the oil colour tubes from her original painting box using inductively coupled plasma-optical emission spectroscopy (ICP-OES). Petroviciu et al. [8] applied liquid chromatography with $\mathrm{UV}-\mathrm{Vis}$ and mass spectrometric detection (LC-DADMS) to identify the dyes and their biological sources from Transylvanian ethnographic textiles from the nineteenth to twentieth century and compared the results obtained with the information from a collection of recipes published by the Romanian Academy in 1914. The multitechnique study of red dyes molecules and traditional madder dyeing techniques used during the twentieth century for producing Iranian carpets reported by Chahardoli et al. [9] revealed the use of various synthetic dye sources as well as the efficiency of the traditional organic mordants mentioned by old recipes based on madder dye.

Another group of articles concerned with indoor air quality and environmental conditions impact on various historical materials such as metals, alum-treated wood, sensitive pigments and glass, varnishes and paper. Grøntoft and Marincaş [10] implemented the newly developed Memori methodology, Memori ${ }^{\circledR}$-EWO (Early Warning Organic) dosimeters and passive pollution badge samplers for acetic and formic acids to assess the impact of indoor pollution in selected urban and rural museum spaces in Romania. In order to protect lead seals from VOCs corrosion, Msallamova et al. [11] compared the efficiency of several commercial adsorbents against lead corrosion using lead resistometric probes. Using the same approach, Msallamova et al. [12] examined the corrosion rate induced by several disinfectants on lead seals and selected the most appropriate disinfectants for 
the restoration of historical documents with lead seals. McQueen et al. [13] employed powder X-ray diffraction (XRD) to investigate how $\mathrm{RH}$ and $T$ affect the crystalline stability of alum-treated wooden artefacts and refine the $\mathrm{RH}$ and $T$ limits for these highly hygroscopic artefacts.

Understanding deterioration mechanisms and measurement of quantifiable properties in order to assess the damage was the focus of the articles by Simoen et al. [14], Chua [15], Vyskočilová et al. [16] and Badea and Carşote [17]. The first concerned with a combined microand macro-scale X-ray powder diffraction mapping of degraded orpiment pigment in a seventeenth century still life painting by Martinus Nellius in which the authors demonstrated the in situ formation of secondary metal arsenate and sulfate species and their migration through the paint layer stack they originate from. The second article of this group discusses the degradation of Burmese paintings on zinc supports, as well as the consequential effects of paint materials and artists' techniques to the degradation observed. The last two articles focuses on leather deterioration: Vyskočilová et al. [16] simulated photo-oxidation, oxidation and hydrolysis and investigated the analytical potential of ATR-FTIR technique and micro hot table (MHT) method to assess leather deterioration, while Badea and Carşote [17] identified the key-steps of deterioration in historical leather and proposed a method for quantifying damage using micro differential scanning calorimetry (micro DSC) and MHT method. Badea et al. [18] also reported a recent research concerning the development of halloysite nanoparticles dispersions for enhancing the hydrothermal stability of weakened historical leather.

The study of the information stored in manuscripts and books offered some authors the opportunity of interrogating these objects in novel ways. Fiddyment et al. [19] set up a triboelectric technique for non-invasive sampling of biomolecules on the parchment surface enabling the exploration of biological data associated to parchment documents, whereas Bicchieri et al. [20] studied the micro-objects, both inorganic and organic, associated to either parchment or cellulose fibres, or inks and dirt. Both approaches have the ability to reveal information about manufacture, ageing, livestock economies, handling, conservation and the historic use of the object.

New studies in metals and paintings cleaning are also reported: Baij et al. [21] contributed to a better understanding of the impact of different methods of solvent application on oil paintings and highlighted important differences between these methods; Moretti et al. [22] aimed at developing an efficient methodology for in situ assessing painting surfaces after the laser cleaning using optical coherence tomography (OCT) and reflection
FT-IR spectroscopy complemented with laser induced fluorescence (LIF) spectroscopic measurements; Yiming et al. [23] developed a new kind of eco-friendly gel based on PHB (poly-3-hydroxybutyrate), biodiesel (BD) and dimethyl carbonate (DMC) for the cleaning of wax-based coatings applied on indoor bronzes.

Finally, archaeometric investigations of ceramics from Alcazar of Nájera (Spain) and Byzantine pottery from Păcuiul lui Soare (Romania) archaeological sites were performed by Calparsoro et al. [24] and Bugoi et al. [25] in trying to establish the provenance and/or the consumption and circulation of pottery in specific geographical regions and time periods.

The contributions in this Special Issue focus the chemical aspects of heritage science acknowledging the significance and growing role of chemistry and related fields on preserving our heritage. It is significant that, as splendidly shown by some of the collected articles, the results of scientific analysis are integrated, interpreted and contextualised by close collaboration between researchers with different backgrounds. As a whole, this Special Issue provides a summary of the most recent advances in the field and contributes to an improved or even entirely new understanding of heritage. It may be also useful for the implementation and improvement of analysis, interpretation and management of cultural heritage all around the world. Hopefully, this Special Issue will foster greater collaboration, bring more excellent scientists to the 2020 edition of $\mathrm{ChemCH}$ congress and attract more young researchers into our fold. I am therefore grateful to both the authors and reviewers for having demonstrated the depth and breadth of the research put into play in dealing with the key-challenges of cultural heritage in the twenty-first century. I would also like to heartily thank the editorial team for smooth communication, prompt publication, effectiveness, and earnestness.

For more information: http://www.chemch2018.ro/.

\section{Authors' contributions}

EB guest-edited this collection and wrote this editorial. The author read and approved the final manuscript.

\section{Competing interests}

The authors declare that they have no competing interests.

\section{Author details}

${ }^{1}$ Advanced Research for Cultural Heritage Laboratory (ARCH Lab), National Research and Development Institute for Textile and Leather, Division Leather and Footwear (INCDTP-ICPI), Str. Ion Minulescu 93, 031215 Bucharest, Romania. ${ }^{2}$ Department of Chemistry, Faculty of Sciences, University of Craiova, Calea Bucuresti 107 I, 200512 Craiova, Romania.

Received: 11 November 2019 Accepted: 11 November 2019

Published online: 22 November 2019 


\section{References}

1. Marcaida I, Maguregui M, Morillas $\mathrm{H}$, et al. In situ non-invasive multianalytical methodology to characterize mosaic tesserae from the House of Gilded Cupids, Pompeii. Herit Sci. 2019;7:3. https://doi.org/10.1186/s4049 4-019-0246-1.

2. Nasa J, Biale G, Sabatini F, et al. Synthetic materials in art: a new comprehensive approach for the characterization of multi-material artworks by analytical pyrolysis. Herit Sci. 2019;7:8. https://doi.org/10.1186/s4049 4-019-0251-4.

3. Manea B, Lechintan M, Popescu G, et al. Looking beyond appearances: a multi-analytical approach on the prehistoric clay weights. Herit Sci. 2019;7:88. https://doi.org/10.1186/s40494-019-0326-2.

4. Artesani A, Ghirardello M, Mosca S, et al. Combined photoluminescence and Raman microscopy for the identification of modern pigments: explanatory examples on cross-sections from Russian avant-garde paintings. Herit Sci. 2019;7:17. https://doi.org/10.1186/s40494-019-0258-x.

5. Vetter W, Latini I, Schreiner M. Azurite in medieval illuminated manuscripts: a reflection-FTIR study concerning the characterization of binding media. Herit Sci. 2019;7:21. https://doi.org/10.1186/s40494-019-0262-1.

6. Albrecht M, Noord O, Meloni S, et al. Jan Steen's ground layers analysed with principal component analysis. Herit Sci. 2019;7:53. https://doi. org/10.1186/s40494-019-0295-5.

7. Caruso F, Mantellato S, Streeton NLW, et al. Unveiling Harriet Backer: ICPOES study for the characterisation of the colour tubes from her original paint box. Herit Sci. 2019;7:1. https://doi.org/10.1186/s40494-018-0244-8.

8. Petroviciu I, Teodorescu I, Albu F, et al. Dyes and biological sources in nineteenth to twentieth century ethnographic textiles from Transylvania, Romania. Herit Sci. 2019;7:15. https://doi.org/10.1186/s40494-019-0255-0.

9. Chahardoli Z, Vanden Berghe I, Mazzeo R. Twentieth century Iranian carpets: investigation of red dye molecules and study of traditional madder dyeing techniques. Herit Sci. 2019;7:57. https://doi.org/10.1186/s4049 4-019-0288-4.

10. Grøntoft T, Marincas $O$. Indoor air pollution impact on cultural heritage in an urban and a rural location in Romania: the National military museum in Bucharest and the Tismana monastery in Gorj County. Herit Sci. 2018;6:73. https://doi.org/10.1186/s40494-018-0238-6.

11. Msallamova S, Kouril M, Strachotova KC, et al. Protection of lead in an environment containing acetic acid vapour by using adsorbents and their characterization. Herit Sci. 2019;7:76. https://doi.org/10.1186/s4049 4-019-0317-3.

12. Msallamova S, Kouril M, Strachotova KC, et al. Historical lead seals and the influence of disinfectants on the lead corrosion rate. Herit Sci. 2019;7:18. https://doi.org/10.1186/s40494-019-0260-3.

13. McQueen CMA, Steindal CC, Narygina O, et al. Temperature- and humidity-induced changes in alum-treated wood: a qualitative $X$-ray diffraction study. Herit Sci. 2018;6:66. https://doi.org/10.1186/s40494-018-0232-z.
14. Simoen J, Meyer S, Vanmeert F, et al. Combined micro- and macro scale $X$-ray powder diffraction mapping of degraded Orpiment paint in a 17th century still life painting by Martinus Nellius. Herit Sci. 2019;7:83. https:// doi.org/10.1186/s40494-019-0324-4

15. Chua L. Whitish haze, soapy globules: micro-analysis of degraded burmese paintings on zinc supports. Herit Sci. 2019;7:46. https://doi. org/10.1186/s40494-019-0287-5.

16. Vyskočilová G, Ebersbach M, Kopecká R, et al. Model study of the leather degradation by oxidation and hydrolysis. Herit Sci. 2019;7:26. https://doi. org/10.1186/s40494-019-0269-7.

17. Carsote C, Badea E. Micro differential scanning calorimetry and micro hot table method for quantifying deterioration of historical leather. Herit Sci. 2019;7:48. https://doi.org/10.1186/s40494-019-0292-8.

18. Badea E, Carşote C, Hadîmbu E, et al. The effect of halloysite nanotubes dispersions on vegetable-tanned leather thermal stability. Herit Sci. 2019;7:68. https://doi.org/10.1186/s40494-019-0310-x.

19. Fiddyment S, Teasdale MD, Vnouček J, et al. So you want to do biocodicology? A field guide to the biological analysis of parchment. Herit Sci. 2019;7:35. https://doi.org/10.1186/s40494-019-0278-6.

20. Bicchieri M, Biocca P, Colaizzi P, et al. Microscopic observations of paper and parchment: the archaeology of small objects. Herit Sci. 2019;7:47. https://doi.org/10.1186/s40494-019-0291-9.

21. Baij L, Astefanei A, Hermans J, et al. Solvent-mediated extraction of fatty acids in bilayer oil paint models: a comparative analysis of solvent application methods. Herit Sci. 2019;7:31. https://doi.org/10.1186/s4049 4-019-0273-y.

22. Moretti $P$, Iwanicka M, Melessanaki $K$, et al. Laser cleaning of paintings: in situ optimization of operative parameters through non-invasive assessment by optical coherence tomography (OCT), reflection FT-IR spectroscopy and laser induced fluorescence spectroscopy (LIF). Herit Sci. 2019;7:44. https://doi.org/10.1186/s40494-019-0284-8.

23. Yiming J, Sciutto G, Prati S, et al. A new bio-based organogel for the removal of wax coating from indoor bronze surfaces. Herit Sci. 2019;7:34. https://doi.org/10.1186/s40494-019-0276-8.

24. Calparsoro E, Sanchez-Garmendia U, Arana G, et al. An archaeometric approach to the majolica pottery from Alcazar of Nájera archaeological site. Herit Sci. 2019;7:33. https://doi.org/10.1186/s40494-019-0275-9.

25. Bugoi $R$, Talmațchi $C$, Haită $C$, et al. Archaeometric characterization of Byzantine pottery from Păcuiul lui Soare. Herit Sci. 2019;7:55. https://doi. org/10.1186/s40494-019-0298-2.

\section{Publisher's Note}

Springer Nature remains neutral with regard to jurisdictional claims in published maps and institutional affiliations.

\section{Submit your manuscript to a SpringerOpen ${ }^{\circ}$ journal and benefit from:}

- Convenient online submission

- Rigorous peer review

- Open access: articles freely available online

- High visibility within the field

Retaining the copyright to your article

Submit your next manuscript at springeropen.com 